\title{
Morphological variability of the fruits of seven pomegranate (Punica granatum L.) cultivars grown in Messaad region in central Algeria
}

\author{
Mohamed Lahouel ${ }^{(1,2)}$, Safia Belhadj ${ }^{(1)}$ \\ (1) Ziane Achour University of Djelfa. Faculty of Nature and Life Sciences. Route de Moudjebara. Djelfa (Algeria). E-mail: \\ lahouelmohamed08@gmail.com \\ (2) Mouloud Mammeri University of Tizi Ouzou (Algeria).
}

Received 5 February 2021, accepted 24 January 2022, available online 7 February 2022.

This article is distributed under the terms and conditions of the CC-BY License (http://creativecommons.org/licenses/by/4.0)

Description of the subject. In the Messaad region, in central Algeria, pomegranate (Punica granatum L.) is one of the main fruit crops in agricultural systems after apricot.

Objectives. To explore cultivar diversity, a study of the morphological variability of pomegranate fruits and seeds was carried out on the fruits of seven pomegranate cultivars: Khadraye KH1, Hamraye HM1, Senin Alouj SL1 from Messaad orchards, AM2 (Amourah) from Amourah orchards, Khadraye KH3, Mezabi MZ3, Senin Alouj SL3 from Zaccar orchards.

Method. Analysis of variance (ANOVA), a principal Component Analysis (PCA) followed by an Ascending Hierarchical Classification (AHC) based on quantitative morphological parameters are used.

Results. The results show similarities between classes according to which four main classes were grouped. The first class $\mathrm{C} 1$ consists of two cultivars (KH1 and SL1 of Messaad), while the second class C2 consists of one cultivar, HM1 of Messaad. The third class C3 consists of the very characteristic Romane Amourah (AM2) and the fourth and last class C4 includes all cultivars of the third station of Zaccar. The evaluation of the qualitative characteristics of color and taste of the fruit by a panel of amateur tasters reveals significant dissimilarities and similarities.

Conclusions. The results presented in this work clearly justify the variability and its interest in the preservation, exploitation and valorization of this genetic material, and for improving cultivated varieties of pomegranate that show appreciable economic performances.

Keywords. Aril, antioxidant activity, functional foods, Punicaceae, cultivar selection.

Variabilité morphologique des fruits de sept cultivars de grenadier (Punica granatum L.) cultivés dans la région de Messaad, au centre de l'Algérie

Description du sujet. Dans la région de Messaad, au centre de l'Algérie, le grenadier (Punica granatum L.) est l'une des principales cultures fruitières des systèmes agricoles après l'abricot.

Objectifs. Pour explorer la diversité des cultivars, une étude de la variabilité morphologique des fruits et des graines du grenadier a été réalisée sur les fruits de sept cultivars de grenade : Khadraye KH1, Hamraye HM1, Senin Alouj SL1 des vergers de Messaad, AM2 (Amourah) des vergers d'Amourah, Khadraye KH3, Mezabi MZ3, Senin Alouj SL3 des vergers de Zaccar. Méthode. Une analyse de la variance (ANOVA), une Analyse en Composantes Principales (ACP) suivie d'une Classification Ascendante Hiérarchique (CAH) basée sur des paramètres morphologiques quantitatifs sont utilisées.

Résultats. Les résultats montrent des similitudes entre les classes, selon lesquelles quatre classes principales ont été regroupées. La première classe C1 est constituée de deux cultivars (KH1 et SL1 de Messaad), tandis que la seconde classe C2 est constituée d'un cultivar, HM1 de Messaad. La troisième classe C3 est constituée d'un grenadier très caractéristique, Romane Amourah (AM2) et la quatrième et dernière classe $\mathrm{C} 4$ comprend tous les cultivars de la troisième station de Zaccar. L'évaluation des caractéristiques qualitatives de la couleur et du goût du fruit par un panel de dégustateurs amateurs révèle des dissemblances et des similitudes significatives.

Conclusions. Les résultats présentés dans ce travail justifient clairement la variabilité et son intérêt pour la préservation, l'exploitation et la valorisation de ce matériel génétique, ainsi que pour l'amélioration des variétés cultivées de grenadier qui présentent des performances économiques appréciables.

Mots-clés. Arille, activité antioxidante, aliment fonctionnel, Punicaceae, sélection de cultivars. 


\section{INTRODUCTION}

Pomegranate (Punica granatum L.) is from the Punicaceae (L.) or the Lythraceae (APG II, 2003) botanical family which includes only one genus and two species, the other one, little-known, being P. protopunica Balf. peculiar and endemic to Socotra Island (Yemen). The plant is drought tolerant, winter hardy and can thrive well under desert conditions (Morton, 1987; Aseri et al., 2008; Chandra et al., 2010). It is a native tree from Iran, Afghanistan, and south east Turkey. The species is a fruit tree with deciduous leaves which, in recent years, has seen great expansion in several countries, especially those with Mediterranean-like climates, where fruits of excellent quality can be produced. The pomegranate tree is well adapted to many different climates and soils; very often it grows in poor soils (Martınez et al., 2006; Soriano et al., 2011; Crivellaro et al., 2013; Hernández et al., 2014).

Pomegranate had a rich symbolic role in the art, literature, and religion of numerous cultures. In nearly every part of the globe where the pomegranate grew, it came to represent fundamental dualities: life and death, inside and out, many and one (Ruis, 2015).

Recently, pomegranate has established itself as a functional food of increasing interest, both economically and within the scientific community, which has generated a significant increase in publications focused mainly on its characteristics, benefits, and nutritional composition (Melgarejo et al., 2020). Indeed, pomegranate is a species of great importance for not only the food, pharmaceutical and cosmetic industries but also for the traditional medicine, it is regarded as "a Pharmacy unto itself" in Ayurveda which specifically uses it to treat infections, inflammations and fungal diseases. Many pomegranate cultivars can be considered as a source of fiber and natural antioxidants to develop or enhance functional foods (Alcaraz-Mármola et al., 2017; Khwairakpam et al., 2018; Souza et al., 2018).

Its therapeutic properties have been used to treat different conditions (cardiovascular, neurological, diabetes and cancer) for hundreds of years. Numerous studies have recently shown the antioxidant, anti-inflammatory and anti-tumoral properties of pomegranate as cited by Khwairakpam et al. (2018) and Sreekumar et al. (2014). As well, inhibition of tumor invasion has been proven in several experimental models of urological tumors such as in prostate cancer (Chéchile-Toniolo, 2012). It has always been allocated for fresh consumption, but recently there is a huge demand for industrial processing to obtain pomegranate juice, jams, etc. (Martinez et al., 2006).

Worldwide P. granatum production has expanded greatly due to recent evidence on the fruit health attributes (Borochov-Neori et al., 2011). Current global production estimates for pomegranate are unavailable (Stover \& Mercure, 2007). From the data provided by different researchers and associations, the total world area dedicated to pomegranate cultivation is well above 300,000 ha, of which more than $76 \%$ is found in five countries (India, Iran, China, Turkey and the USA), the estimation of world pomegranate production is more than 3 million tons. The data provided does not, therefore, correspond to an exact year and constitutes an estimation based on different sources (Melgarejo-Sánchez et al., 2013).

In the 2013/2014 crop year, Algeria's location in the Mediterranean basin makes it one of the most productive pomegranate countries with 81,390 tons, where the cultivated area was estimated at 9,439 ha with a yield of $8,620 \mathrm{~kg} \cdot \mathrm{ha}^{-1}$ (MADR, 2016). Consequently, the country occupies a significant position among pomegranate-producing countries despite the technical and economic difficulties, such as exportation encountered in this sector.

With a pomegranate area of 1,094 ha, i.e. $11.59 \%$ of the total cultivated area in Algeria, a production of 10,704 tons, i.e. more than $13.15 \%$ of the national production of pomegranate, a yield of $9,784 \mathrm{~kg} \cdot \mathrm{ha}^{-1}$ and the quality of its fruits, the region of Messaad, which traditionally includes the areas of Messaad, Ain El Ibel, Zaccar, Moudjebara, Amourah and Faid El Botma, in central Algeria, has become a promising area for this activity (DSA, 2017). In addition, P. granatum varieties from Messaad, some of which are subject to severe erosion, adapt well to aridosols despite the limiting conditions such as physical, chemical and climatic characteristics. The development of these soils, their management and the development of these crops is of paramount importance given the size of this land in Algeria (Lahouel, 2014).

The objective of this work was to determine the phenotypic variability among several P. granatum cultivars grown in these regions and to highlight its economic interest. A morphological study is conducted by the examination of the characteristics of the fruits and the seeds of seven cultivars from three different locations.

\section{MATERIALS AND METHODS}

\subsection{Study location and environmental conditions}

The study took place in the region located south of Djelfa district in central Algeria. Three different locations: Messaad, Amourah and Zaccar sites were retained.

The evolution of rainfall and temperatures reflects the recent climate upheaval experienced in recent years 
in North Africa and the Great Maghreb (Nouaceur et al., 2013). During 16 years (2002-2017), it is mentioned that July is the hottest month for the three stations Messaad, Amourah and Zaccar with respectively average values of $29.23{ }^{\circ} \mathrm{C}, 28.04{ }^{\circ} \mathrm{C}$ and $27.28^{\circ} \mathrm{C}$, the coldest month is January with respectively $7.27^{\circ} \mathrm{C}, 6.08^{\circ} \mathrm{C}$ and $5.32{ }^{\circ} \mathrm{C}$. During the same period, precipitation is low with a large inter-monthly and inter-annual variability and it is particularly concentrated in winter and autumn and is lower in summer (June-July) (Figure 1) (ONM, 2020).

The inter-annual variability of precipitation is significant and is $182.80 \mathrm{~mm}$ for the year 2002 and $146.5 \mathrm{~mm}$ for the year 2017 with a standard deviation of $63.37 \mathrm{~mm}$ in Messaad. It is $202.80 \mathrm{~mm}$ for the year 2002 and $166.5 \mathrm{~mm}$ for the year 2017 with a standard
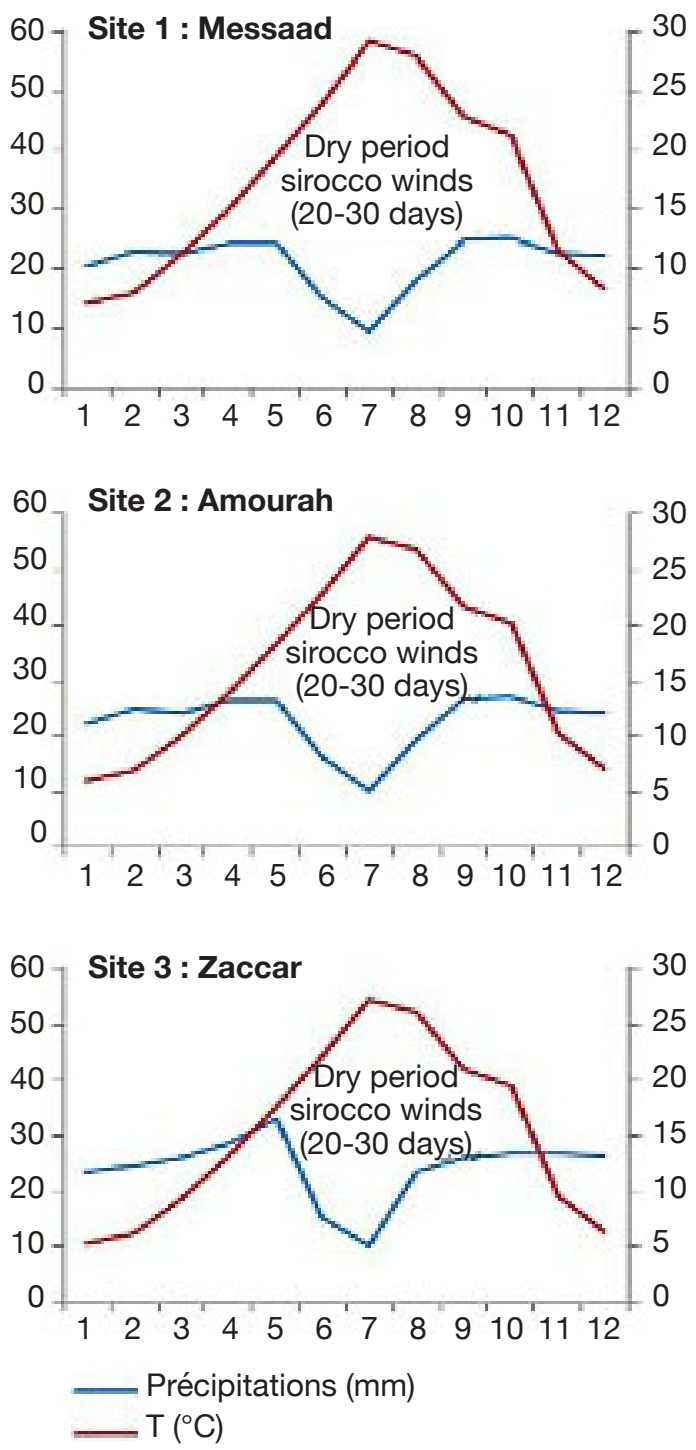

Figure 1. Umbrothermal diagram of the Messaad area (2002-2017) - Diagramme ombrothermique de la zone de Messaad (2002-2017). deviation of $63.67 \mathrm{~mm}$ in Amourah and about of $212.80 \mathrm{~mm}$ for the year 2002 and $176.5 \mathrm{~mm}$ for the year 2017 with a standard deviation of $67 \mathrm{~mm}$ in Zaccar. The dry period in Messaad and Amourah is longer than in Zaccar station (Figure 1). The main characteristic of the prevailing winds in the region is the frequency in summer of the sirocco, of desertic origin, hot and dry, whose duration may vary from 20 to 30 days per year (Figure 1) (ONM, 2020). Due to the altitude effect (Table 1), the sites Messaad and Amourah are located in the bioclimatic arid stage with a cool winter while the station Zaccar is located in arid bioclimate with cold winter on the Emberger's climatogram (data not shown).

In the absence of soil maps on the region, except for that of Pouget (1976), our description will take into account this former document. The gradient related to soil categories shows their paucity and fragility as a general comment. The soil profile of the three sites is classified as calcimagnesic xeric soil with a calcareous crust (limestone), which means that the soils are calcareous from the surface; this results in an alkaline $\mathrm{pH}$, sometimes close to neutrality and saturated absorbent complexes. These characteristics therefore play only a very limited role in soil differentiation, but also as ecological factors responsible for some ecological determinism (edaphic ecological group: psamophytes, halophytes, gypsophytes; indicator species for edaphic factors: sand, salt, gypsum, etc.). Their richness in nitrogen, especially the rhizospheric area, is the result of the root activity and the microbial biomass in the soil/root interface (Pouget, 1980; Lahouel et al., 2016).

\subsection{Plant material}

Our study was conducted during the P.granatum fruiting season of 2018 in Messaad region. The selected plant material (KH1, HM1, SL1, AM2, KH3, MZ3 and SL3) is among the main cultivars existing in the central region of Algeria (Table 1).

The consecutive fruit's ripening of cultivars SL1 of Messaad, MZ3 of Zaccar, KH3 and SL3 of Zaccar at end of September occurs with more or less high temperatures (between $20-23{ }^{\circ} \mathrm{C}$ ). During the month of October, the temperature declines to less than $18^{\circ} \mathrm{C}$, the cultivars HM1 of Messaad, AM2 of Amourah and KH1 (Messaad) reach respectively maturity and can be harvested.

According to the phenological stages of pomegranate (Table 2), fruit setting and growth coincide with high temperatures, low rainfall and sirocco winds, which occur during the summer period. This situation pushes the farmers to practice regular irrigation in order to maintain their crops, formative and fruit tree pruning and organic manuring in the objective to increase production. 


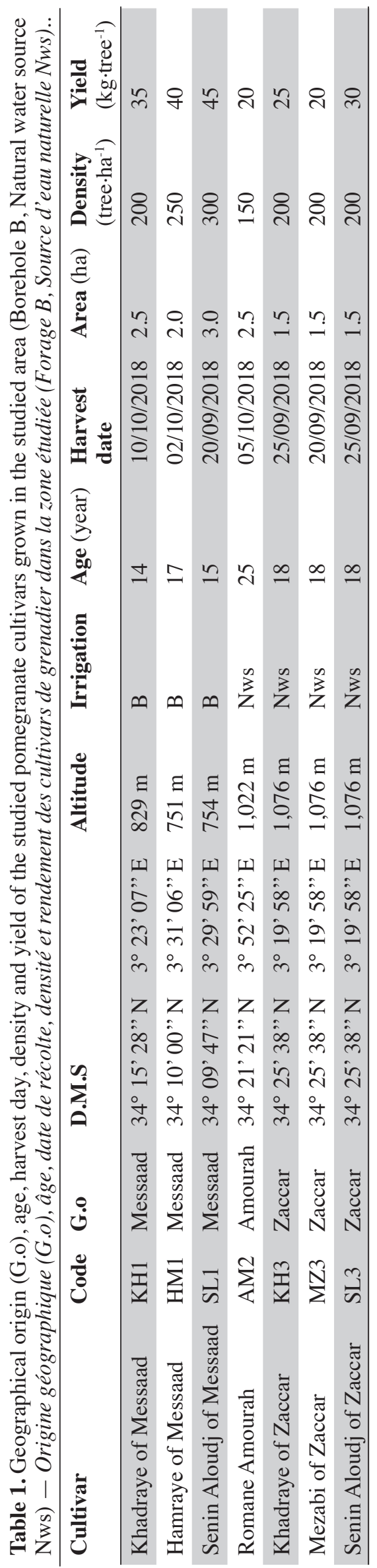

\subsection{Morphological parameters studied}

The study was conducted on seven cultivars. Thirty trees were randomly selected from each orchard, 10 fruits were randomly picked from each tree and 20 seeds were manually extracted randomly from each fruit. The morphological parameters studied were measured on 300 fruits (300 repetitions) and 6,000 seeds $(6,000$ repetitions) for each cultivar (Figure 2).

Quantitative parameters. The diameter and the length of the fruit, the length of the crown, the length and the width of the seeds, the length and the width of the tegmen (woody portion) were measured, using a digital caliper with an accuracy of $0.01 \mathrm{~mm}$. Fruit and rind weights were measured with a scale with an accuracy of $0.1 \mathrm{~g}$ (Table 3).

Qualitative parameters. For the external fruit shape coded by Fs and the presence of the nipple on the fruit coded by Pn; these two parameters are measured with the naked eye and classified according to the UPOV (2012) descriptor (Table 4).

Taste and color. To measure the sensory characteristics for the taste and the color of the P. granatum fruit, a test centered on consumers was used with a panel of inexperienced amateur tasters (Watts et al., 1991) of thirty people at the different stations. The amateur taster panels (pilot consumer panels usually consisting of 30 to 50 inexperienced people) are selected from the workers who are employed (non-trained tasters) in the orchard. The focus should be on selecting a group of tasters comparable to the target consumer population that uses the product (representative of consumers). Thirty people were chosen for each site in order to discriminate between the three tastes: sweet, sour-sweet, sour for each cultivar. To record the results, our method consists of asking subjects to rate the perceived degree of each of the above mentioned sensory characteristics of the fruit. The rating is held as one point for each selected taste.

Expert taster panels are used for product-oriented testing. These panels are usually small and made up of 5 to 15 tasters who have been chosen for their sensory acuity and have received special training for the task (Bacle et al., 2009). Unfortunately, there are no expert tasters in our district who have received special training to taste the fruit.

\subsection{Statistical analysis}

Statistical analyses have been performed using XLSTAT software (version 2014 for Windows). Abasic descriptive statistical analysis was followed by an Analysis of variance and a Principal Component Analysis (PCA). An Ascending Hierarchical Classification (AHC) was 
Table 2. Phenological stages of the pomegranate in the Messaad region - Stades phénologiques du grenadier dans la région de Messaad.

\begin{tabular}{|c|c|c|c|c|c|c|c|c|c|c|}
\hline Month & Nov & Dec & Jan & Feb & March & April & June & July & Sep & Oct \\
\hline \multirow{2}{*}{$\begin{array}{l}\text { Phenological } \\
\text { stage }\end{array}$} & \multirow{2}{*}{\multicolumn{3}{|c|}{$\begin{array}{c}\text { Leaf fall } \\
\text { and } \\
\text { vegetative rest }\end{array}$}} & \multirow{2}{*}{\multicolumn{2}{|c|}{$\begin{array}{l}\text { Bud } \\
\text { burst }\end{array}$}} & Flowering & \multirow{2}{*}{\multicolumn{3}{|c|}{$\begin{array}{l}\text { Fruit setting } \\
\text { Fruit growth }\end{array}$}} & \multirow{2}{*}{$\begin{array}{l}\text { Fruit } \\
\text { ripening }\end{array}$} \\
\hline & & & & & & Leaf growth & & & & \\
\hline
\end{tabular}

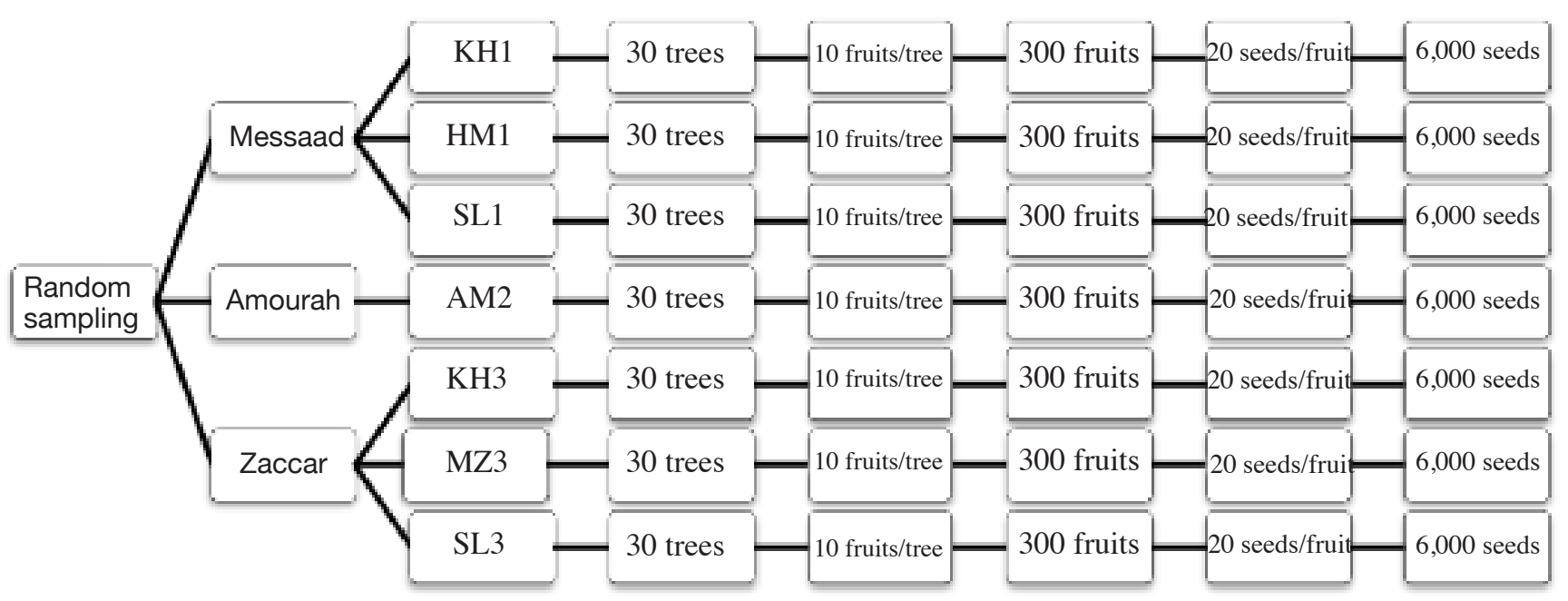

Figure 2. Sampling experimental design - Protocole expérimental de l'échantillonnage.

Table 3. Main studied quantitative morphological parameters for the fruits and the seeds - Principaux paramètres morphologiques quantitatifs étudiés pour les fruits et les graines.

\begin{tabular}{lllllllll}
\hline Parameter & $\begin{array}{l}\text { Fruit length } \\
\text { without crown } \\
(\mathrm{mm})\end{array}$ & $\begin{array}{l}\text { Fruit } \\
\text { diameter } \\
(\mathrm{mm})\end{array}$ & $\begin{array}{l}\text { Fruit weight } \\
(\mathrm{g})\end{array}$ & $\begin{array}{l}\text { Crown } \\
\text { length } \\
(\mathrm{mm})\end{array}$ & $\begin{array}{l}\text { Rind weight }+ \\
\text { carpellary } \\
\text { membranes }(\mathrm{g})\end{array}$ & $\begin{array}{l}\text { Seeds } \\
\text { yield }\end{array}$ & $\begin{array}{l}\text { Seed } \\
\text { length } \\
(\mathrm{mm})\end{array}$ & $\begin{array}{l}\text { Seed } \\
\text { width } \\
(\mathrm{mm})\end{array}$ \\
\hline Code* & $\mathrm{L} 1$ & $\mathrm{D} 1$ & $\mathrm{FW}$ & $\mathrm{L} 2$ & $\mathrm{Rw}+\mathrm{Cm}$ & $\mathrm{Sy}$ & $\mathrm{Ls}$ & $\mathrm{Ws}$ \\
\hline & $\begin{array}{l}\text { Tegmen length } \\
(\mathrm{mm})\end{array}$ & $\begin{array}{l}\text { Tegmen width } \\
(\mathrm{mm})\end{array}$ & $\begin{array}{l}\text { Fruit form } \\
\text { index }\end{array}$ & $\begin{array}{l}\text { Fruit calyx } \\
\text { index }\end{array}$ & & & & \\
\hline Code* $^{*}$ & $\mathrm{Lt}$ & $\mathrm{Wt}$ & $\mathrm{If}$ & $\mathrm{Ic}$ & & & \\
\hline
\end{tabular}

$* \mathrm{Sy}=[\mathrm{Fw}-(\mathrm{Rw}+\mathrm{Cm}) / \mathrm{Fw}] \times 100(\%), \mathrm{If}=(\mathrm{D} 1 / \mathrm{L} 1) \times 100(\%), \mathrm{Ic}=[\mathrm{L} 2 /(\mathrm{L} 1+\mathrm{L} 2)] \times 100(\%)$.

also performed. This analysis has been applied to the data for hierarchical associations using the Ward's method.

\section{RESULTS}

\subsection{Quantitative parameters}

Showing a very highly significant effect, all cultivar lengths and diameters L1 and D1 are more than $80 \mathrm{~mm}$, excepted for AM2 (Amourah) for which it was registered a length of $75.21 \mathrm{~mm}$ and a diameter close to $70 \mathrm{~mm}$. Our samples diameters show values between nearly $70 \mathrm{~mm}$ for AM2 (Amourah) and $91.95 \mathrm{~mm}$ for SL3 (Zaccar). At the same time, L1 and D1 are positively correlated. Fruits with the longest lengths have the largest diameters such as HM1 of Messaad, SL3 and KH3 of Zaccar (Table 5).

For the fruit weight $(\mathrm{Fw})$, this agronomically interesting variable, signification is very high between cultivars. The average Fw varies between a maximum value of $317.39 \mathrm{~g}$ for HM1 (Messaad) and $135.85 \mathrm{~g}$ for AM2 (Amourah) as a minimum value. Cultivars KH3, MZ3 and SL3 of Zaccar have average weights of $271.25 \mathrm{~g}, 287.78 \mathrm{~g}$ and $276.21 \mathrm{~g}$ respectively, which are, relatively, close to each other. Another agronomically valuable variable, seed yield, shows a 
Table 4. Qualitative variables measured for the fruits and the seeds (adapted from UPOV, 2012) - Variables qualitatives mesurées pour les fruits et les grains (adapté de UPOV, 2012).

\begin{tabular}{lll}
\hline Variable & Code & Value \\
\hline Fruit shape & Fs & $1,3,5,7$ \\
Presence of nipple & Pn & 1,9 \\
Fruit color & Fc & $1,2,3,4,5,6,7,8,9,10$ \\
Seed color & Sc & $1,2,3,4,5,6,7$ \\
Taste & Ts & Sour; sour-sweet; sweet \\
\hline
\end{tabular}

Fs: 1 , round - rond; 3 , ovate - ovoüde; 5 , oval - ovale;

7, elliptical - elliptique; Pn: 1, absent on fruit - absent sur le fruit; 9 , present on fruit - présent sur le fruit; Fc: 1 , orange - orange $; 2$, orange red - orange rouge; 3 , pink - rose; 4, pink red - rose rouge; 5 , medium red - rouge moyen; 6 , red purple - rouge pourpre; 7 , purple - pourpre; 8 , dark purple - pourpre foncé; 9 , light green - vert clair; 10 , yellow red - jaune rouge; Sc: 1 , white - blanc; 2 , light pink - rose clair; 3 , medium pink - rose moyen; 4 , dark pink - rose foncé; 5 , light red - rouge clair; 6 , medium red - rouge moyen; 7 , dark red - rouge foncé.

very high significant effect. HM1 (Messaad) records the highest value with $73.33 \%$, and in the same site, SL1 (Messaad) has the lowest value with $62.03 \%$. Although the Fw of SL3 (Zaccar) is higher than that of KH3 (Zaccar), the seed yield of KH3 with $66.32 \%$ is higher than that of SL3 (Zaccar) with $65.11 \%$. Statistically, Fw is positively correlated with the rind and carpellary membranes weight $\mathrm{Rw}+\mathrm{Cm}$, consequently they have almost the same quantity of the edible part (Tables $\mathbf{5}$ and 6).

Highly significantly differences among cultivars are recorded, the crown length is between $17 \mathrm{~mm}$ and $23 \mathrm{~mm}$, this is a mean value for all cultivars. It is correlated positively with L1 and D1 which present the size of the fruit, thus the fruits of HM1 of Messaad and SL3 of Zaccar have the longest crowns (Tables 5 and 6). Despite the non-significance in values, the Ic records are between $18.57 \%$ for $\mathrm{KH} 3$ (Zaccar) and $19.17 \%$ for HM1 (Messaad). The If of the seven studied cultivars is always less or near to 100 , indicating that the equatorial diameter in all fruits is smaller than the fruit length without calyx (between $89.98 \%$ for SL1Messaad and $96.94 \%$ for KH3-Zaccar).

The values of the quantitative parameters for the seeds show a statistically very high significance between cultivars excepted for the tegmen length. $L s$ is between $9.35 \mathrm{~mm}$ for AM2 (Amourah) and $11.66 \mathrm{~mm}$ for KH1 (Messaad); a Ws between $6.21 \mathrm{~mm}$ for AM2 (Amourah) and $7.53 \mathrm{~mm}$ for SL1 (Messaad). For the woody part, $L t$ is between $6.97 \mathrm{~mm}$ for AM2 (Amourah) and $7.85 \mathrm{~mm}$ for $\mathrm{KH} 1$ (Messaad), Wt is between $2.93 \mathrm{~mm}$ for AM2 (Amourah) and $3.22 \mathrm{~mm}$ for KH1 (Messaad). Cultivar AM2 (Amourah) shows the lowest values for all the studied parameters. In addition, the correlation matrix shows a positive dependence between $L s$ and $L t$ with a coefficient of 0.94 and between $W s$ and $W t$ with a coefficient of 0.88 (Tables 5 and 6).

The Pearson squared coefficient $\left(\mathrm{R}^{2}\right)$ gives an idea on the proportion of variability in one variable which may be explained by the other. Through our statistical analyses (Table 5), the quantitative fruit characteristics (L1, D1, Fw, L2, Rw+Cm and Sy) and the quantitative seed parameters $(L s, W s$ and $W t)$ and their differences can be strongly related to cultivar types, these results are confirmed by the ANOVA which shows a very high significance for all these parameters (dependent variables) and which is explained statistically by the "cultivar" effect (independent factor).

\subsection{Qualitative parameters}

Most cultivars have a round to ovate fruit shape without nipple, results are confirmed by the If values (Table 5) which are mostly near $100 \%$.

Cultivars show variations in fruit color from light to dark color. SL1 (Messaad) and SL3 (Zaccar) have a yellow red fruit color, KH1 (Messaad) and KH3 (Zaccar) have the same fruit color light green; AM2 (Amourah) has a red purple fruit color (Figure 3).

Cultivars KH1 (Messaad), KH3 and MZ3 (Zaccar) have the same seed color: dark red. HM1 (Messaad), SL1 (Messaad) and SL3 (Zaccar) have medium to light seed color (Table 7, Figure 3). For the pomegranate flavor, our sample is divided into two groups; the first one: KH1, SL1 (Messaad), AM2 (Amourah) and SL3 (Zaccar) have a sweet taste while the second one: HM1 (Messaad), KH3 and MZ3 (Zaccar) is characterized by a sour-sweet taste (Table 7).

\subsection{Principal Component Analysis (PCA) and Ascending Hierarchical Classification (AHC)}

In general, all the traits studied are positively correlated with each other except Sy but the intensity of the binding differs from each other. The parameters $\mathrm{L} 1, \mathrm{D} 1, \mathrm{~L} 2, \mathrm{Rw}+\mathrm{Cm}$ and $W s$ are positively correlated with $\mathrm{Fw}$, with highly significant values (close to value 1). Tegmen length and width $L t, W t$ have a highly significant correlation with $L s$ and $W s$ (Table 6). The seed yield is negatively correlated with $\mathrm{Rw}+\mathrm{Cm}$ with a value of -0.5 , indicating the influence of the peel weight on the fruit edible part.

The first three principal components explain more than $94 \%$ of the total variation. Almost $85.97 \%$ of the observed variability (Figure 4) is explained by the first two components concerning morphological 
parameters (F1 and F2 axes). The first component, F1, which counts $68.59 \%$ of the total variance, is positively related to fruit size (L1, D1, Fw, L2 and $\mathrm{Rw}+\mathrm{Cm}$ ) and seed size (Ls, Ws, Lt and $W t$ ) (Figure 4), while F2 counts $17.38 \%$ of the total variance. The F2 axis is positively correlated to the biometric measurements of the seed $(L s, W s, L t$ and $W t$ ), while inversely correlated to those of the fruit (L1, D1, Fw, L2 and Sy) (Figure 4).

Messaad's Hamraye (HM1) cultivar registers a more negative result on the Y-axis of the second principal component and thus confirms its differentiation from other cultivars which is explained essentially by maximum values recorded for parameters like the fruits weight. Some cultivars such as KH1 and SL1 of Messaad are relatively close to each other on the X-axis (F1). Ecotypes $\mathrm{KH} 3$, MZ3 and SL3 of Zaccar scored positively on the $\mathrm{X}$ axis (F1) and separated from the others on the $\mathrm{Y}$ axis (F2); these two groups are characterized by large fruit size compared to the others. AM2 (Amourah) is negatively correlated with $\mathrm{F} 1$ and this is related to its small fruit and seed size (Figure 4).

The results obtained from $\mathrm{AHC}$, using the agglomerative method based only on the quantitative morphological characteristics of fruits and seeds, are presented as dendrograms (Figure 5), in which four main classes were grouped together. The first class $\mathrm{C} 1$ consists of two cultivars: KH1 (Messaad) and SL1 (Messaad), while the second class $\mathrm{C} 2$ includes only one particular cultivar: HM1 (Messaad). The third class $\mathrm{C} 3$ consists of the very characteristic Romane Amourah cultivar (AM2) and the fourth and last class $\mathrm{C} 4$ includes the cultivar of the third station of Zaccar, with morphologically similar characteristics. 
Table 6. Correlation matrix (Pearson [n]) - Matrice de corrélation (Pearson [n]).

\begin{tabular}{|c|c|c|c|c|c|c|c|c|c|c|}
\hline Variables & L1 & D1 & Fw & L2 & $\mathrm{Rw}+\mathrm{Cm}$ & Sy & Ls & Ws & $\mathbf{L t}$ & Wt \\
\hline L1 & 1 & 0,97 & 0,94 & 0,98 & 0,93 & $-0,23$ & 0,55 & $\mathbf{0 , 8 0}$ & 0,41 & 0,61 \\
\hline D1 & $\mathbf{0 , 9 7}$ & 1 & 0,96 & 0,91 & $\mathbf{0 , 9 0}$ & $-0,10$ & 0,52 & 0,74 & 0,39 & 0,53 \\
\hline Fw & 0,94 & 0,96 & 1 & 0,91 & 0,86 & 0,01 & 0,50 & 0,79 & 0,29 & 0,56 \\
\hline L2 & 0,98 & 0,91 & 0,91 & 1 & $\mathbf{0 , 8 9}$ & $-0,22$ & 0,50 & $\mathbf{0 , 8 2}$ & 0,32 & 0,62 \\
\hline $\mathrm{Rw}+\mathrm{Cm}$ & 0,93 & 0,90 & 0,86 & 0,89 & 1 & $-0,50$ & 0,60 & 0,90 & 0,50 & 0,70 \\
\hline Sy & $-0,23$ & $-0,10$ & 0,01 & $-0,22$ & $-0,50$ & 1 & $-0,33$ & $-0,46$ & $-0,46$ & $-0,45$ \\
\hline Ls & 0,55 & 0,52 & 0,50 & 0,50 & 0,60 & $-0,33$ & 1 & 0,69 & $\mathbf{0 , 9 4}$ & $\mathbf{0 , 7 6}$ \\
\hline$W s$ & $\mathbf{0 , 8 0}$ & 0,74 & 0,79 & 0,82 & 0,90 & $-0,46$ & 0,69 & 1 & 0,53 & $\mathbf{0 , 8 8}$ \\
\hline$L t$ & 0,41 & 0,39 & 0,29 & 0,32 & 0,50 & $-0,46$ & 0,94 & 0,53 & 1 & 0,70 \\
\hline$W t$ & 0,61 & 0,53 & 0,56 & 0,62 & 0,70 & $-0,45$ & 0,76 & $\mathbf{0 , 8 8}$ & 0,70 & 1 \\
\hline
\end{tabular}
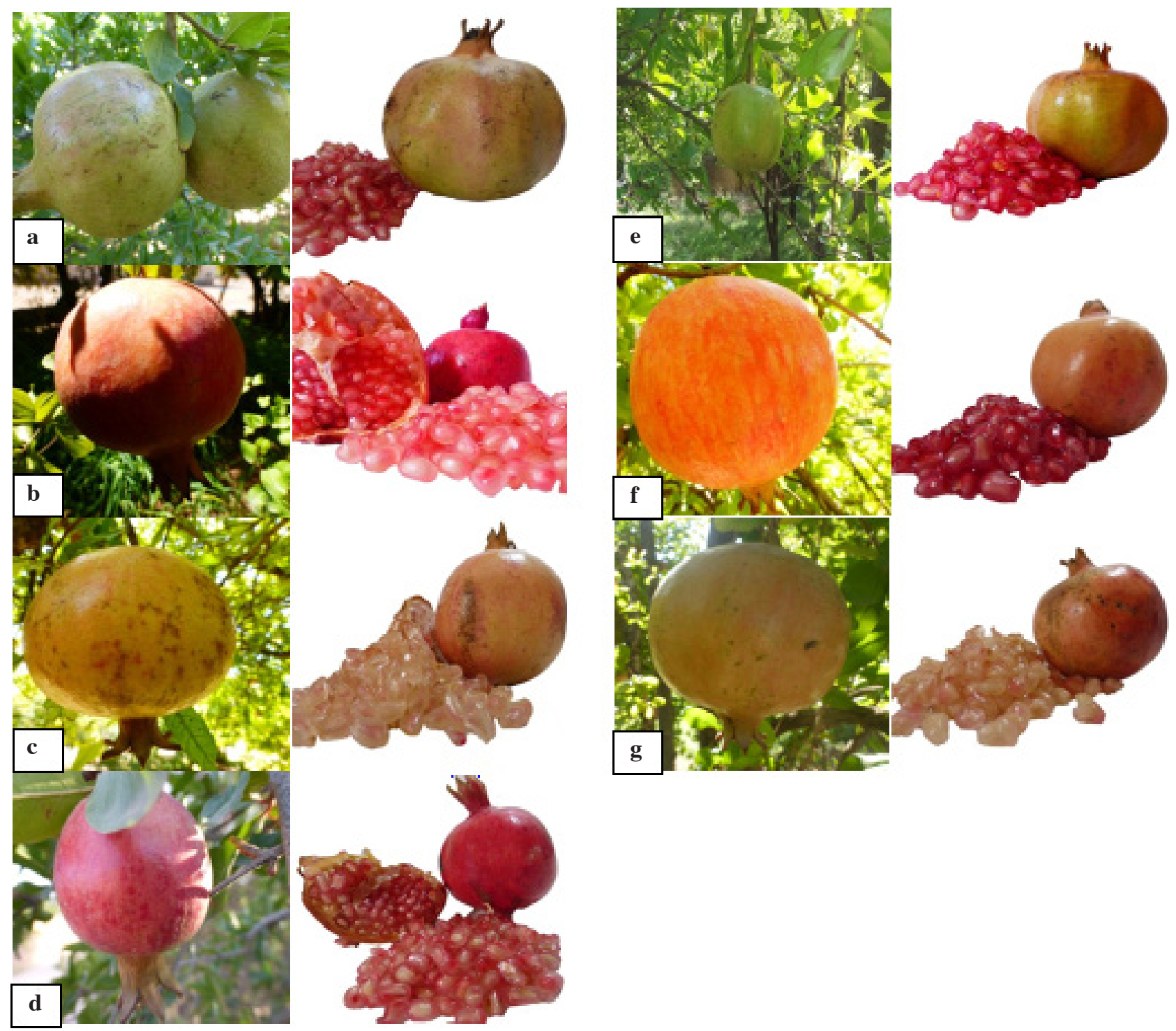

Figure 3. Fruits and seeds - Fruits et graines.

a: KH1 (Messaad); b: HM1 (Messaad); c: SL1 (Messaad); d: AM2 (Amourah); e: KH3 (Zaccar; f: MZ3 (Zaccar); g: SL3 (Zaccar). 
Table 7. Mean values registered for the studied qualitative morphological parameters of pomegranate fruits and seeds - Valeurs moyennes des paramètres morphologiques qualitatifs étudiés des fruits et graines de grenadier.

\begin{tabular}{|c|c|c|c|c|c|c|c|}
\hline \multirow[t]{2}{*}{ Fruit } & \multicolumn{2}{|c|}{ Fruit shape (frequency \%) } & \multicolumn{2}{|c|}{$\begin{array}{l}\text { Presence of nipple } \\
\text { (frequency \%) }\end{array}$} & \multirow[t]{2}{*}{ Fruit color } & \multirow[t]{2}{*}{ Seed color } & \multirow[t]{2}{*}{ Taste } \\
\hline & Round & Ovate & Absent & Present & & & \\
\hline KH1 Messaad & 64.00 & 36.00 & 100.00 & 0 & Light green & Dark red & Sweet \\
\hline HM1 Messaad & 62.33 & 37.67 & 100.00 & 0 & Orange red & Medium pink & Sour-sweet \\
\hline SL1 Messaad & 79.00 & 21.00 & 100.00 & 0 & Yellow red & White & Sweet \\
\hline AM2 Amourah & 53.33 & 46.67 & 100.00 & 0 & Red purple & Light red & Sweet \\
\hline KH3 Zaccar & 42.67 & 57.33 & 100.00 & 0 & Light green & Dark red & Sour-sweet \\
\hline MZ3 Zaccar & 61.33 & 38.67 & 100.00 & 0 & Orange red & Dark red & Sour-sweet \\
\hline SL3 Zaccar & 84.67 & 15.33 & 100.00 & 0 & Yellow red & White & Sweet \\
\hline
\end{tabular}

Biplot (axes F1 + F2: 85.97\%)

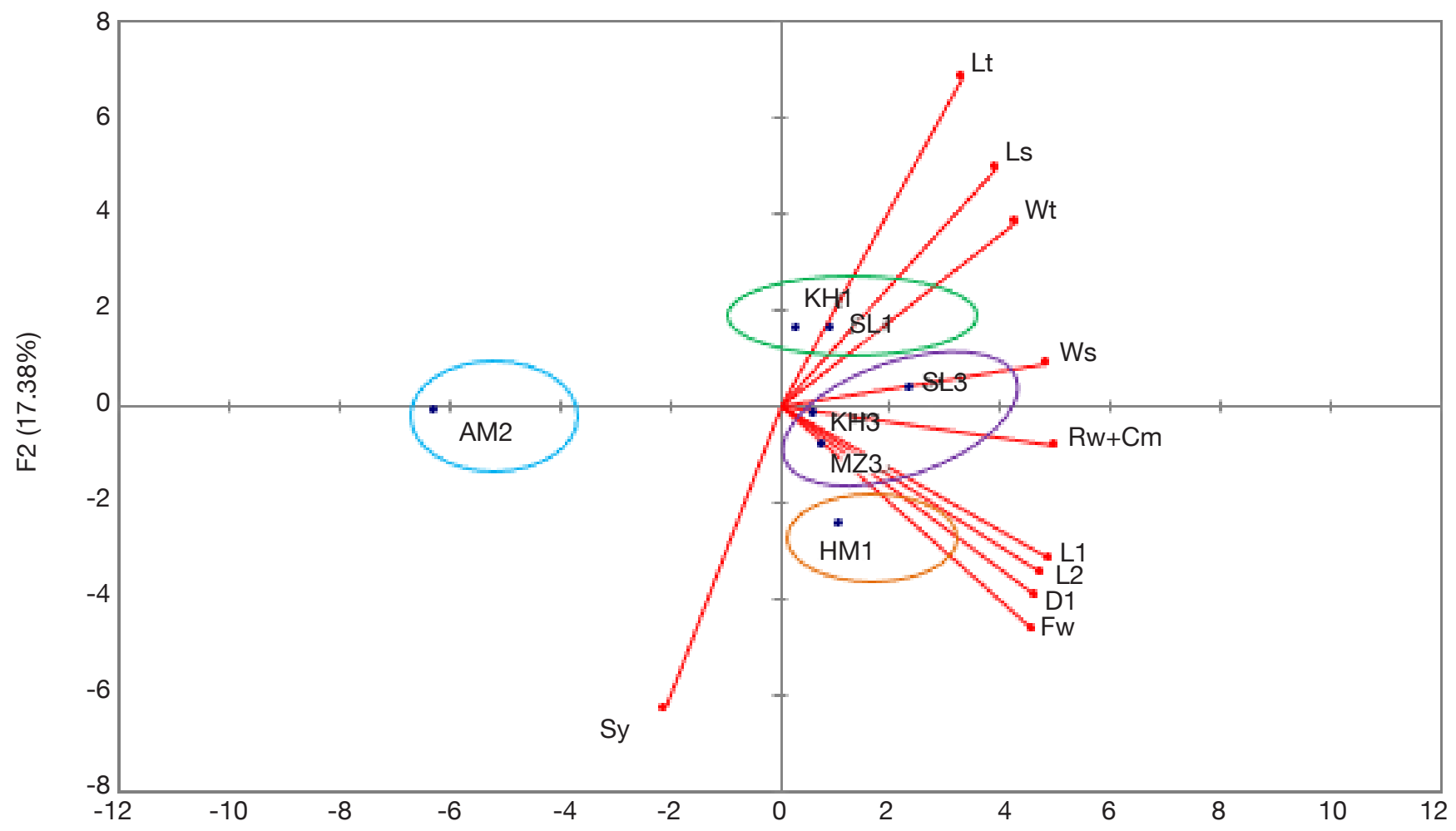

Figure 4. Principal Component Analysis (PCA) Biplot - Analyse en Composantes Principales (ACP) Biplot.

\section{DISCUSSION}

\subsection{Quantitative parameters}

In Mars \& Sayadi (1992) study, the fruits with the greatest height are those of Zehri $(8.2 \mathrm{~cm})$ and Kalaii $(8.1 \mathrm{~cm})$ varieties. The fruits with the highest equatorial diameter are found on Kalaii $(8.9 \mathrm{~cm})$ and Zehri $(8.8 \mathrm{~cm})$. The smallest pomegranates are those of the Spanish variety $(7.9 \mathrm{~cm})$ while Tapia-Campos et al. (2021) recorded $8.92 \mathrm{~cm}$ as a mean value for polar diameter, $8.14 \mathrm{~cm}$ as a mean value for equatorial diameter in 16 pomegranate genotypes studied.

For our samples, all cultivar lengths are classified as long, except for AM2 (Amourah) which is considered as medium. Comparing to a Tunisian study (Mars \& Marrakchi, 1999) for 30 accessions, lengths recorded show a great variability between short, medium and long sizes. For diameters, this result ranks all cultivars as large referring to the $P$. granatum descriptor (NRCP, 2005).

For the fruit weight, our samples are practically in the same range, comparing to results recorded by 


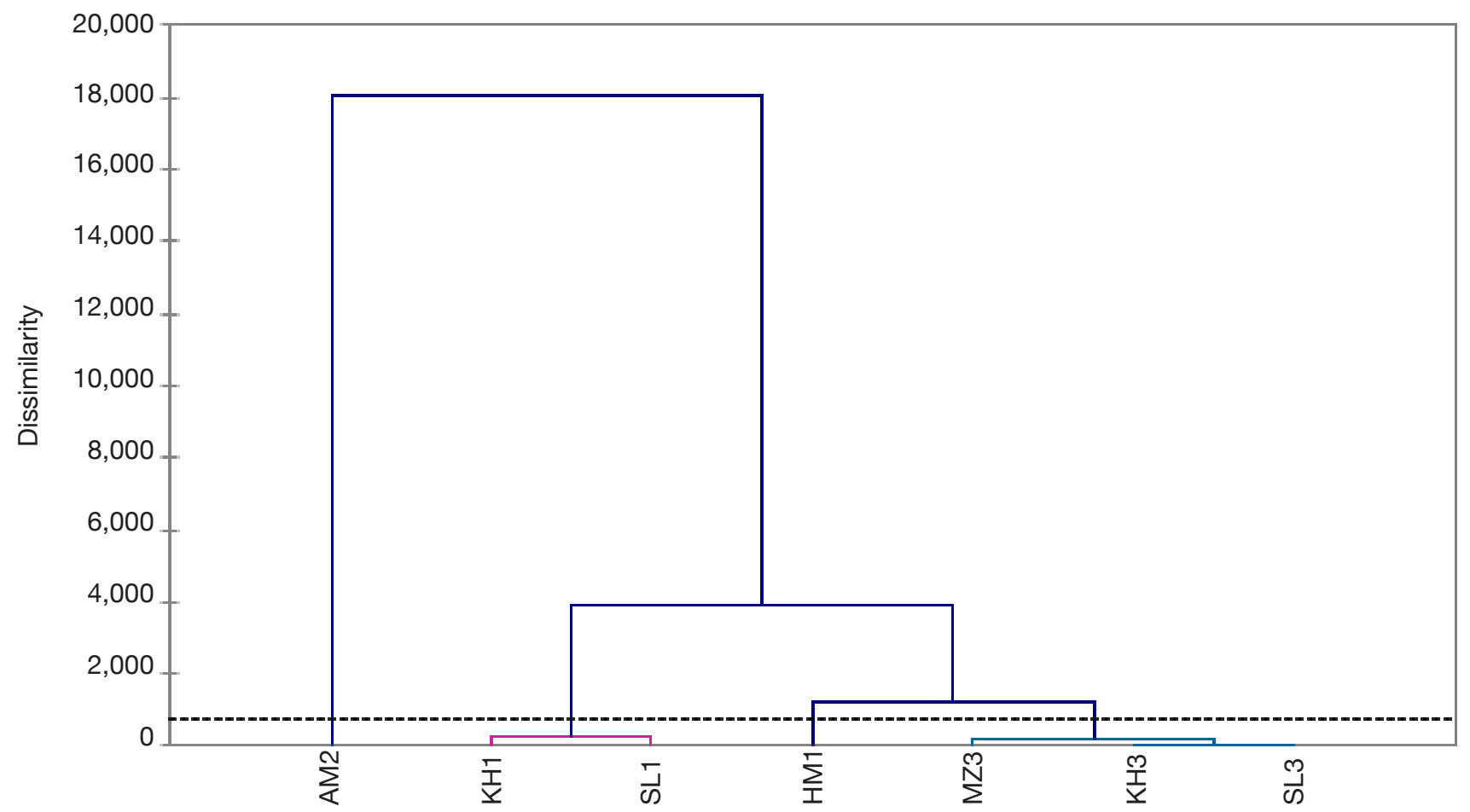

Figure 5. Ascending Hierarchical Classification (AHC) based on the quantitative morphological characteristics of the fruits and the seeds - Classification Ascendante Hiérarchique (CAH) basée sur les caractéristiques morphologiques quantitatives des fruits et des graines.

Martinez et al. (2006) which reported between $251.05 \mathrm{~g}$ as minimum and $421.10 \mathrm{~g}$ as maximum values in the characterization of five Spanish P. granatum. For Mars \& Sayadi (1992), values between $292 \mathrm{~g}$ as minimum and $400 \mathrm{~g}$ as maximum were recorded for the study of five pomegranate varieties. Fruit size, rind weight, total aril weight, 100-aril weight, juice weight and aril width were found to have a strong positive correlation $(p<0.01)$ with fruit weight (Chandra et al., 2012). Kumari et al. (2019) specified that a highest critical difference at 5\% were 13.21 for fruit weight. Fruit weight was positively correlated with fruit peel thickness $(\mathrm{r}=+0.11)$. In Tapia-Campos et al. (2021) study, authors reported that the polar diameter, equatorial diameter and fruit weight can explain more than $90 \%$ of the variation using a PCA test in first factor PC1.

In our case, fruit length, fruit diameter, crown length and rind weight are highly correlated with fruit weight. These results are confirmed by Mars \& Sayadi (1992) where the heaviest fruits have the highest measured fruit parameters.

For the seed yield, Hernández et al. (2014) recorded for the Spanish $P$. granatum accessions values varying between $52.67 \%$ and $65.87 \%$, while for Martınez et al. (2012) the values are between $53.4 \%$ and $61.2 \%$ for the Moroccan cultivars. For a selection of Tunisian pomegranate (Mansour et al., 2011), the percentage of seeds is between $57.72 \%$ and $78.90 \%$. According to these studies, our samples have considerable seed yields.

According to Martınez et al. (2012), the morphometric variables measured in the fruits have economic interests, and not just because of their acceptance or rejection by the consumer, but additionally because of their influence upon industrial manipulation of this fruit; for instance, cultivars with a high calyx index are more sensitive to calyx breakage, and therefore their external aspect becoming negatively affected.

Al-Yahyai et al. (2009) claim that the variability in fruit shape during the period of commercial harvest, fruit harvesting based solely on size and shape for all cultivars are not sufficient to ensure optimum maturity for fruit utilization and performance during postharvest handling and storage. Other indicators such as the changes in physico-chemical fruit attributes at maturity may be taken into account when assessing readiness to harvest to ensure optimum income returns to growers.

For the seed parameters ( $L s, W s, L t$ and $W t$ ), all are positively correlated. $L s$ and $W s$ have a high value of correlation coefficient. Martınez et al. (2006) showed a positive correlation between these parameters excepted between $W s$ and $L t$ which is negative. 


\subsection{Qualitative parameters}

For the taste, all cultivars are suitable for fresh consumption. Kumari et al. (2019) confirmed that $P$. granatum is quite popular among consumers for its striking, sweet acidic taste and refreshing arils. According to Boussaa et al. (2018), the consumers showed significant differences in their overall liking and in their satisfaction degree for all studied sensory attributes. The descriptive panel was not able to find differences in the intensity of the individual sensory attributes under study (sourness, sweetness, and astringency) as affected by the microclimates, the consumers scored better their satisfaction degrees for both aroma and taste.

Messaad, Amourah and Zaccar cultivars showed variations in fruit color from yellow red, light green to red purple. Dafny-Yalin et al. (2010) indicated that the skin color of the peel is the first trait affecting consumer choices ; however, the color of the peels cannot predict the appropriate day of harvest and aril quality. Color varies significantly between cultivars, from whiteyellow through orange-pink, to intense red and purple.

The color of the fruit and the seeds showed significant dissimilarities and similarities from white to dark red. All cultivars are presenting appropriate organoleptic characteristics for fresh consumption. These dissimilarities are very useful for breeding; an interesting research work conducted by Jalikop et al. (2010) revealed that selecting genotypes with vividly colored arils is useful in breeding varieties free from aril browning. Other authors (Borochov-Neori et al., 2011) revealed on the basis of RP-HPLC analysis of the arils' anthocyanins under climate effects, that anthocyanin accumulation, which conferred fruit's red color, changed inversely to the season's temperatures. Cyanidins were generally more abundant but delphinidin accumulation was enhanced in cooler season. Monoglucosylated anthocyanins prevailed at cooler temperatures and subsided during seasonal warming with a concomitant increase in diglucoside proportion. The findings can benefit breeding and agricultural efforts to enhance pomegranate quality, especially in the face of "global warming".

According to Boussaa et al. (2018), descriptive sensory analysis revealed differences between oasis and regular orchard with full sun exposure in the aril color intensity. Arils from fruits cultivated under full shade oasis system were characterized by high intensity of the red color (trained panel) which made them well appreciated by the consumer panel.

\subsection{Principal Component Analysis (PCA) and Ascending Hierarchical Classification (AHC)}

Whereas statistically significant differences were observed through ANOVA in the evaluated morphological parameters (both in the fruit size and in the whole seed), the PCA and AHC analysis show similarities in many cultivars and discriminate them in four classes. Analysis revealed variability related to morphological parameters, supported by several other parameters.

The first class (KH1-Messaad and SL1-Messaad) is characterized by a sweet and acceptable taste, a high yield, $35 \mathrm{~kg} \cdot$ tree $^{-1}$ for KH1 (Messaad) classified as medium production and $45 \mathrm{~kg} \cdot$ tree $^{-1}$ for SL1 (Messaad) (Table 1) classified as high production referring to Melgarejo (1993) reported by Martinez et al. (2006). The second class (HM1 of Messaad) which shows differences with the remaining cultivars by the size, has an acceptable taste and a high production of $40 \mathrm{~kg} \cdot$ tree $^{-1}$ (Table 1). These three less aged cultivars receive permanent care through agricultural practices, including regular irrigation in order to sustain crops, formative and fruit tree pruning and organic manuring in the objective to increase production. The third class is formed by AM2 (Amourah), the oldest cultivar characterized by smaller size, a sweet and acceptable taste and a low yield of $20 \mathrm{~kg} \cdot$ tree $^{-1}$ (Table 1). Even though these low records, yet, this cultivar remains a resource to be preserved and valorized. The fourth class (Zaccar cultivars: KH3, MZ3 and SL3) older than Messaad's is marked by similar morphological aspects with a large fruit size, but with low to medium productions (20-30 kg.tree ${ }^{-1}$ ) (Table 1) according to the levels established by Melgarejo (1993) reported by Martinez et al. (2006).

The climatic gradient and cultural practices, especially the type of irrigation between drip irrigation from a borehole and traditional channel irrigation from a natural water source, contribute significantly to this variability among cultivars. Singh (2004) noted highly significant inter-varietal differences in vegetative growth, yield, fruit size, fruit cracking, number and weight of arils in arid to semi-arid ecosystems and interesting results were recorded in terms of performance for the desired traits. In addition, Mir et al. (2012) stipulate that even though pomegranate grows well in low fertility soils, production can be increased by application of manures and fertilizers. Galindo et al. (2017) and Mellisho et al. (2012) added that regular and strategic drip irrigation during the fruit ripening period (under water stress) improves the fruit size and its chemical characteristics linked to taste and color.

The cultivar variability allows choices for growers according to their different technical, climatic and edaphic conditions, the discrimination can be pronounced by other punctual researches like molecular markers. Studies as of Jbir et al. (2014) showed that cultivars from southern Tunisia represent a considerable common genetic base despite their phenotypic differences and misnames: synonymy and/or homonymy reported. Naming problems may 
explain all the results obtained. They reported that pomegranate cultivars are locally named according to their geographical origins or according to the agronomic characteristics of the fruit as reported by Mars \& Marrakchi (1999). While the results reported by Ajal et al. (2014) showed clearly that the ISSR molecular markers used during the study proved to be efficient in terms of highlighting molecular polymorphism in pomegranate as well as exploring the genetic relationships between the cultivars involved, the analysis of these markers revealed a great diversity of the accessions studied.

The description of pomegranate germplasm is based mainly on pomological and agronomic criteria and genetic studies are rare. The use of other biochemical and molecular markers such as isozymes and RAPD fingerprints could supply complementary useful information as for many other fruit species (Khadari et al., 1995; Ouazzani et al., 1995; Trifi et al., 1998; Mars \& Marrakchi, 1999; Mars, 2000).

\section{CONCLUSIONS}

In conclusion, we can orient the choice for growers to a ranking of our cultivars according to several considerations. Referring specifically to the economic point of view of high yield, acceptable taste quality and lastly size, it is necessary to affirm that the cultivars of Messaad KH1, HM1 and SL1 are the most interesting for the agricultural and industrial use. According to their performances of parameters linked to the fruit and the seed, the cultivars of the Zaccar site (KH3, MZ3 and SL3) are the most vigorous and still a phytogenetic resource to be valorized by improving the cultural practices in the orchard especially the type of irrigation used. As for the adaptation to the different gradients related to the climatic and edaphic conditions, the cultivars of Messaad show an interesting vigor and give acceptable yields due essentially to the correct cultural practices; those of Zaccar and Amourah give a negative response by reducing their yield under traditional irrigation by channel in these conditions.

Based on these different findings, the results reveal the strengths of our experimental device to differentiate the seven cultivars from the point of view of performance and economic interest and its limitations to highlight the chemical differences and variability at the level of molecular polymorphism that can guide growers to make the right choices. It is essential in the future to complete this work by a chemical analysis and a mineral composition of the fruit. A completed study of the molecular polymorphism of the cultivars in our case using genetic markers such as Random amplification of polymorphic DNA (RAPD), simple sequence repeats (SSRs), or amplified fragment length polymorphism (AFLP) to highlight the molecular diversity is more than necessary.

\section{Bibliography}

Ajal E. et al., 2014. Exploration des marqueurs ISSR pour l'étude du polymorphisme moléculaire du grenadier (Punica granatum L.) au Maroc. Rev. Reg. Arides, 35, 393-398.

Alcaraz-Mármola F. et al., 2017. Characterization of twenty pomegranate (Punica granatum L.) cultivars grown in Spain: aptitudes for fresh consumption and processing. Sci. Hortic., 219, 152-160, doi.org /10.1016/j. scienta.2017.03.008

Al-Yahyai R., Al-Said F. \& Opara L., 2009. Fruit growth characteristics of four pomegranate cultivars from northern Oman. Fruits, 64(6), 335-341, doi.org/10.1051/ fruits/2009029

APG II., 2003. An update of the Angiosperm Phylogeny Group classification for the orders and families of flowering plants: APG II. Bot. J. Linn. Soc., 141, 399436, doi.org /10.1111/boj.12385

Aseri G.K. et al., 2008. Biofertilizers improve plant growth, fruit yield, nutrition, metabolism and rhizosphere enzyme activities of pomegranate (Punica granatum L.) in Indian Thar Desert. Sci. Hortic., 117, 130-135, doi. org/10.1016/j.scienta.2008.03.014

Bacle I. et al., 2009. Évaluation sensorielle. Manuel méthodologique. $3^{e}$ éd. Paris : Tec \& Doc.

Borochov-Neori H. et al., 2011. Climate effects on anthocyanin accumulation and composition in the pomegranate (Punica granatum L.) fruit arils. J. Agric. Food.Chem., 59, 5325-5334, doi.org/10.1021/jf2003688

Boussaa F. et al., 2018. Cropping system contributes largely to fruit composition and sensory properties of pomegranate (Punica granatum L. var. Gabsi). S. Afr. J. Bot., 115, 170-178, doi.org/10.1016/j.sajb.2018.01.016

Chandra R. et al., 2010. Origin, history and domestication of pomegranate. Fruit Veg. Cereal Sci. Biotechnol., 4, 16.

Chandra R. et al., 2012. Variability studies of physicochemical properties of pomegranate (Punica granatum L.) using a scoring technique. Fruits, 68(2), 135-146, doi.org/10.1051/fruits/2013059

Chéchile-Toniolo G.E., 2012. Usefulness of pomegranate in prostate cancer. II International Symposium on the Pomegranate. Options Mediterr. A, 103, 311-320, doi. org/10.1111/j.1479-8298.2011.00443.x

Crivellaro A. \& Schweingruber F.H., 2013. Atlas of wood, bark and pith anatomy of eastern mediterranean trees and shrubs. Berlin: Springer, 402-403, doi.org/10.1007/9783-642-37235-3

Dafny-Yalin.M. et al., 2010. Color, sugars and organic acids composition in aril juices and peel homogenates prepared from different pomegranate accessions. J. Agric. Food Chem., 58, 4342-4352, doi.org/10.1021/jf904337t 
DSA (Direction des Services Agricoles), 2017. Rapport sur la wilaya de Djelfa. Djelfa, Algérie : Direction des Services Agricoles de la wilaya de Djelfa.

Galindo A. et al., 2017. Water stress at the end of the pomegranate fruit ripening stage produces earlier harvest and improves fruit quality. Sci. Hortic., 226, 6874, doi.org/10.1016/j.scienta.2017.08.029

Hernández F. et al., 2014. Fruit quality characterization of seven pomegranate accessions (Punica granatum L.) grown in Southeast of Spain. Sci. Hortic., 175, 174-180, doi.org /10.1016/j.scienta.2014.05.035

Jalikop S.H.,Venugopalan R.\& Kumar R., 2010.Association of fruit traits and aril browning in pomegranate (Punica granatum L.). Euphytica, 174, 137-141, doi. org/10.1007/s10681-010-0158-3

Jbir R. et al., 2014. Étude de la diversité moléculaire de cultivars de grenadier (Punica granatum L.) du sud tunisien. Rev. Reg. Arides, 35, 119-124.

Khadari B., Lashermes Ph. \& Kjellberg F., 1995. RAPD fingerprints for identification and genetic characterization of fig (Ficus carica L.) genotypes. J. Genet. Breed., 49, 77-86.

Khwairakpam A.D. et al., 2018. Possible use of Punica granatum (pomegranate) in cancer therapy. Pharmacol. Res., 133, 53-64, doi.org/10.1016/j.phrs.2018.04.021

Kumari S. et al., 2019. Correlation between different morphological traits of pomegranate (Punica granatum). Int. J. Curr. Microbiol. Appl. Sci, 8(1), 981-985, doi. org/10.20546/ijcmas.2019.801.106

Lahouel M., 2014. Caractérisation de l'environnement racinaire du pistachier de l'Atlas, de l'olivier et du grenadier dans la région de Messaad. Mémoire de magister : Université Ziane Achour, Djelfa (Algérie).

Lahouel M., Belhadj S. \& Nait Kaci Boudiaf M., 2016. Pistacia atlantica rhizosphere characterization under arid climate. XVI GREMPA Meeting on almonds and pistachios. Options Mediterr. A, 119, 187-191.

MADR (Ministère de l'Agriculture et du Développement Rural), 2016. Rapport sur les arbres fruitiers en Algérie. Alger : Ministère de l'Agriculture et du Développement Rural.

Mansour E. et al., 2011. Selection of pomegranate (Punica granatum L.) in south-eastern Tunisia. Afr. J. Biotechnol., 10(46), 9352-9361, doi.org/10.5897/ AJB 10.1959

Mars M., 2000. Pomegranate plant material: genetic resources and breeding. Production, processing and marketing of pomegranate in the Mediterranean region: advances in research and technology. Options Mediterr. A, 42, 55-62.

Mars M. \& Marrakchi M., 1999. Diversity of pomegranate germplasm in Tunisia. Genet. Ressour. Crop Evol., 46, 461-467, doi.org/10.1023/A:1008774221687

Mars M. \& Sayadi S., 1992. Étude comparative de la qualité des fruits de cinq variétés de grenadier (Punica granatum L.). Rev. Reg. Arides, 3, 45-57.
Martinez J.J. et al., 2006. Seed characterisation of five new pomegranate (Punica granatum L.) varieties.Sci.Hortic., 110, 241-246, doi.org/10.1016/j.scienta.2006.07.018

Martinez J.J. et al., 2012. Physico-chemical characterization of six pomegranate cultivars from Morocco: processing and fresh market aptitudes. Sci. Hortic., 140, 100-106, doi.org/10.1016/j.scienta.2012.04.002

Melgarejo P. et al., 2020. Pomegranate (Punica granatum L.) a dry pericarp fruit with fleshy seeds. Trends Food Sci. Technol., 102, 232-236, doi.org/10.1016/j. tifs.2020.02.014

Melgarejo-Sánchez P. et al., 2013. The pomegranate tree in the world: new cultivars and uses. Acta Hortic., 1089, 327-332, doi.org/10.17660/ActaHortic.2015.1089.43

Mellisho C.D. et al., 2012. Pomegranate (Punica granatum L.) fruit response to different deficit irrigation conditions. Agric. Water Manage., 114, 30-36, doi.org/10.1016/j. agwat.2012.06.010

Mir M.M. et al., 2012. Quality evaluation of pomegranate crop - A review. Int. J. Agric. Biol., 14, 658-667.

Morton J.F., 1987. Fruits of warm climates. Brattleboro, VT, USA: Echo Point Books \& Media, 352-355.

Nouaceur Z., Laignel B. \& Turki I., 2013. Changements climatiques au Maghreb: vers des conditions plus humides et plus chaudes sur le littoral algérien ? PhysioGéo, 7, 307-323, doi.org/10.4000/physiogeo.3671

NRCP (National Research Centre on Pomegranate), 2005. DUS test guidelines: pomegranate species (Punica granatum L.). Maharashtra, India: National Research Centre on Pomegranate, http://www.plantauthority.gov. in, (2019).

ONM (Office National de Météorologie), 2020. Données climatiques de la station de Djelfa (période 2000-2019). Alger : Office National de Météorologie.

Ouazzani N., Lumaret R. \& Villemur P., 1995. Apport du polymorphisme alloenzymatique à l'identification variétale de l'olivier (Olea europea L.). Agronomie (EDP Sciences), 15, 31-37.

Pouget M., 1976. Pédologie : région de Messaad-Ä̈n El Ibel. Paris : éd. ORSTOM.

Pouget M., 1980. Le cadre physique. In : Les relations sol-végétation dans les steppes sud-algéroises. Paris: ORSTOM.

Ruis A.R., 2015. Pomegranate and the mediation of balance in early medicine. Gastronomica, 15(01), 22-33, doi:10.1525/gfc.2015.15.1.22

Singh D.B., 2004. Screening of pomegranate (Punica granatum) cultivars for arid ecosystem. Indian J. Agric. Sci., 74, 604-606.

Soriano J.M. et al., 2011. Development and characterization of microsatellite markers in pomegranate (Punica granatum L.).Mol. Breed., 27, 119-128, doi.org/10.1007/ s11032-010-9511-4

Souza A.D., De Souza Jr.JR., Sousa D.C.P. \& Albuquerque U.P., 2018. Punica granatum L. In: Albuquerque U.P., Patil U. \& Màthé Á., eds. Medicinal and aromatic 
plants of the world. Dordrecht: Springer, 413-420, doi. org/10.1007/978-94-024-1552-0

Sreekumar S. et al., 2014. Pomegranate fruit as a rich source of biologically active compounds. BioMed. Res. Int., article ID 686921, 12 p, doi.org/10.1155/2014/686921

Stover E. \& Mercure E.W., 2007. The pomegranate: a new look at the fruit of paradise. Hortic. Sci., 42(5), 10881092.

Tapia-Campos E.etal.,2021.Morphological characterization of southern Jalisco, Mexico, pomegranate genotypes using AFLP markers. Agronomy, 11(1449), doi. org/10.3390/agronomy11081449

Trifi M., Benslimane A.A., Rhouma A. \& Marrakchi M., 1998. Molecular characterization of Tunisian date-palm varieties. In : Proceedings of the First International Conference on Date Palms, 8-10 March 1998, Al-Ain, United Arab Emirates, 183-193.

UPOV (International Union for the Protection of new Varieties of plants), 2012. Pomegranate Punica granatum L. guidelines for the conduct of tests for distinctness, uniformity and stability. TG/PGRAN (proj.3). Geneva, Switzerland : UPOV.

Watts B.M., Ylimaki G.L., Jeffery L.E. \& Elias L.G., 1991. Méthodes de base pour l'évaluation sensorielle des aliments. Ottawa, Canada : éd. CRDI.

(51 ref.) 